\title{
Increased Effluent Dosage Effects on On-Site Wastewater Treatment Systems of Differing Architecture Type
}

\author{
Andrew Gibbons' ${ }^{1}$ Kristofor R. Brye1, Sam Dunn², Edward E. Gbur³, \\ Andrew N. Sharpley ${ }^{1}$, Wen Zhang ${ }^{4}$ \\ ${ }^{1}$ Department of Crop, Soil, and Environmental Sciences, University of Arkansas, Fayetteville, AR, USA \\ ${ }^{2}$ Franklin County Health Unit, Ozark, AR, USA \\ ${ }^{3}$ Agricultural Statistics Laboratory, University of Arkansas, Fayetteville, AR, USA \\ ${ }^{4}$ Department of Civil Engineering, University of Arkansas, Fayetteville, AR, USA \\ Email: kbrye@uark.edu
}

Received 28 May 2015; accepted 27 June 2015; published 30 June 2015

Copyright (C) 2015 by authors and Scientific Research Publishing Inc.

This work is licensed under the Creative Commons Attribution International License (CC BY). http://creativecommons.org/licenses/by/4.0/

cC) (i) Open Access

\section{Abstract}

Approximately $20 \%$ of homes nationwide use an on-site treatment system as a form of household wastewater management. However, approximately $10 \%$ to $20 \%$ of on-site treatment systems malfunction each year, many of which have either failed or exceeded the soil's long-term acceptance rate (LTAR), causing environmental and human health risks. The objective of this field study was to evaluate the effects of soil condition (e.g., wet and dry) and product architecture type [i.e., chamber, gravel-less-pipe (GLP), polystyrene-aggregate, and pipe-and-aggregate] on in-product solution storage and biomat thickness in a profile-limited soil in northwest Arkansas under increased loading rates and to estimate the LTAR for each product. During Phase I of this study (March 13 to October 4, 2013), effluent loading rates were approximately doubled, while rates were approximately quadrupled during Phase II (October 8, 2013 to May 29, 2014), from the maximum allowable loading rate for each product. The pipe-and-tire-chip, $46-\mathrm{cm}$-wide trench pipe-and-gravel, and the $25-\mathrm{cm}$ diameter GLP products had the greatest $(p<0.001)$, while the 31-cm-width and the 5.4-m-long chambers had the lowest $(p<0.001)$ in-product solution storage during wet-soil conditions of Phase I monitoring. The $25-\mathrm{cm}$ diameter GLP product had the greatest $(p<0.001)$, while the 61 -cm-width, $5.4-m$-long chamber had the lowest $(p<0.001)$ in-product solution storage during Phase II. Results of this study indicate that some alternative products may be able to effectively handle effluent loading rates in excess of those currently allowed by the State of Arkansas. Further research will be required to confirm these interpretations. 


\section{Keywords}

\section{On-Site Wastewater, Ozark Highlands, Profile-Limited Soil, Wastewater Treatment}

\section{Introduction}

In 2007, approximately 26.1 million households, or $20 \%$ of all US homes, used on-site treatment systems (i.e., a traditional septic system that consists of a septic tank and distribution to an absorption field) for managing their wastewater [1]. Out of the 26.1 million homes using on-site wastewater treatment systems (OWTS), 13.1 million were in rural areas, 12.3 million were in urban areas, and 774,000 were in cities [1]. The distribution of OWTS users across the US varies by region with 10.1 million in the south, 4.8 million in the midwest, 4.2 million in the northeast, and 2.9 million in the west [1]. Prior to 1990, Arkansas had an estimated 382,467 OWTSs [2].

Arkansas is a largely rural state with varying soil-water characteristics, many of which are unique to Arkansas and affect wastewater disposal system options. On-site treatment system studies and methods for determining functioning procedures have been conducted across the world and have increased understanding of the complex behavior of OWTSs. However, many of the past studies do not apply to Arkansas' specific soil and wetness conditions. Northwest Arkansas has been experiencing a population boom since the mid-1990s, resulting in increased stresses on the existing infrastructure (e.g., roads and water treatment plants) and environmental characteristics, such as natural resources (e.g., land, soil, and water), flora, and fauna species. The majority of the small communities and towns in northwest Arkansas rely on a man-made, surface reservoir on the White River, Beaver Lake, for their drinking water supply. There are also many gas stations, mobile home parks, campsites, and individual homes that also rely on groundwater as a drinking water source. However, much of the topography in northwest Arkansas is karstic [3] [4]. Consequently, groundwater resources are susceptible to pollution from sources such as fertilizers and OWTSs [5]. Therefore, it is important to study OWTS function and limitations within the local region in order to better understand various system types to prevent environmental contamination and human health risks. Considering water is a finite and often controversial resource, and even though water is abundant in northwest Arkansas, on-site wastewater treatment is pivotal to protecting and conserving all water resources. A standard architecture for an on-site wastewater treatment system in Arkansas consists of a 10-cm diameter perforated pipe surrounded by gravel (i.e., pipe-and-aggregate). A 61-cm-wide pipe-and-gravel product is the basis for Arkansas' on-site wastewater treatment system regulations. However, several alternative architecture types, including gravel-less-pipe, chambers, and polystyrene-aggregate, have been developed and their installation have become more frequent without much documentation of performance comparisons.

A few previous studies have been conducted using OWTS products of differing architecture [6]-[10]. However, the experimental conditions in these studies and that of Amerson et al. [11] have not been comparable to a real-world conditions nor have they had similar soil profile limitations that are often present in Arkansas and other locations. A profile-limited soil has characteristics, such as a shallow depth to bedrock, high percentage of clay, and/or fragic properties, that restrict water flow and redistribution at a relatively shallow soil depth. Thus, a profile-limited soil would negatively affect water, and/or effluent, percolation deep into the soil profile, possibly causing a perched water table to form. In extreme climatic conditions, however, the perched water table could rise to the ground surface. Water in the perched water table could also move horizontally throughout the soil, exiting as springs, which could ultimately flow into larger streams, rivers, and lakes or reservoirs [12]. Consequently, contaminants present in the perched water table could also rise to the surface becoming point or non-point source pollution [5] [13].

Tackett et al. [6] monitored the fate of nutrients, such as P and N, in OWTS effluent in-situ using stainless steel lysimeters in a sandy loam in Colorado. In studies by Lowe et al. [7] and Lowe and Siegrist [8], usual loading rates were doubled to test infiltration rate differences among differing architecture types. The soils were sandy and non-profile limited, and the test-cell lengths (i.e., $\sim 67-\mathrm{cm}$ long) were not as long as a practical realworld product. A non-profile-limited soil has no features that would prevent soil water and/or effluent from percolating into and through the profile. As most of the topography in northwest Arkansas is shallow to bedrock, many soils have a seasonally fluctuating water table, with increasing clay content with depth and often with fragic features, and a large percentage of the population relies on surface water for drinking. Therefore, the need 
to study the behavior of absorption-field products of differing architecture types within northwest Arkansas, and other similar regions with profile-limited soils, is critical to provide home owners informed options for on-site household wastewater disposal.

More recently than the studies in Colorado [6]-[8], Mathis et al. [14] studied architecture type (i.e., chamber, gravel-less-pipe, polystyrene-aggregate, and pipe-and-aggregate) effects on in-product solution storage under wet- and dry-soil conditions for the first eight months after dosing began at the Bethel Heights Wastewater Treatment Facility (BHWTF) in Bethel Heights, AR. The study was conducted on a Typic Fragiudult. Thirteen OWTS products were installed [14] (Table 1). Raw effluent that entered the BHTWF directly from its various OWTS tank connections without any other treatment was delivered from a basin to a corresponding absorption-field product. Effluent loading rates for the 13 products were determined by a conservative estimate as stated in the Arkansas rules and regulations in order to mimic real-world applications. Loading rates were between 11.6 to $81.1 \mathrm{~L} \cdot \mathrm{d}^{-1}$ and were determined based on the estimated effluent the soil around each trench could handle, which was based on soil morphological observations [14]. During the study, none of the products failed, where a product failure was characterized as effluent surfacing, which showed that, under the perched seasonal water table and precipitation conditions at the study site, the products were stable and functioned as expected within the first eight months after maximum allowable dosing began [14]. However, the Mathis et al. [14] study did not address potential groundwater contamination.

The soil around the BHWTF is representative of many areas throughout northwest Arkansas with a moderately well-drained silt-loam to clay-loam texture with a fluctuating seasonal water table and fragic soil properties in the top 35 to $65 \mathrm{~cm}$ [15]. Prater et al. [15] extended the study initiated by Mathis et al. [14] and summarized results of in-product storage after three continuous years. Biomat presence and thickness were also monitored after about 1.5 years of effluent dosing, where loading rates were based on soil morphology and the soil storage concept [16] and set at the maximum allowable loading rate by Arkansas regulations. Prater et al. [15] reported that none of the products experienced failure and biomat thickness increased in three products, did not change in nine products, and decreased over time in one product. However, there is speculation that some architecture types can handle increased loading beyond the present maximum rates, which in Arkansas are set equivalent to the standard 61-cm-wide, pipe-and-gravel product [17].

If increases in effluent loading rates are to be justified, it is important to understand the limits of alternative products in order to make better decisions that can ultimately protect human and environmental health as water-borne disease outbreaks can occur from contaminated groundwater [18]. Therefore, the objective of this field

Table 1. Summary of absorption field products by architecture type installed at Bethel Heights, Arkansas between mid-December 2006 and late May 2008. Abbreviated from Mathis et al. [14].

\begin{tabular}{|c|c|c|c|c|}
\hline Architecture type & Product number & Unique product feature & Trench width & Product length \\
\hline & & & $\mathrm{cm}$ & $\mathrm{m}$ \\
\hline \multirow[t]{5}{*}{ Chamber } & 1 & 31-cm width & 46 & 4.4 \\
\hline & 2 & 56-cm width & 61 & 4.4 \\
\hline & 3 & 61-cm width & 61 & 4.4 \\
\hline & 4 & 41-cm width & 41 & 5.4 \\
\hline & 5 & 61-cm width & 61 & 5.4 \\
\hline \multirow[t]{2}{*}{ Gravel-less-pipe } & 6 & 20-cm diameter & 41 & 6.1 \\
\hline & 7 & 25-cm diameter & 46 & 6.1 \\
\hline \multirow[t]{2}{*}{ Polystyrene-aggregate } & 8 & Single bundle & 30 & 6.1 \\
\hline & 9 & Double bundle & 61 & 6.1 \\
\hline \multirow[t]{4}{*}{ Pipe-and-aggregate } & 10 & Gravel & 30 & 6.1 \\
\hline & 11 & Gravel & 46 & 6.1 \\
\hline & 12 & Tire-chip & 61 & 6.1 \\
\hline & 13 & Gravel & 61 & 6.1 \\
\hline
\end{tabular}


study was to evaluate the effects of soil condition (e.g., wet and dry) and absorption-field-product architecture type (i.e., chamber, gravel-less-pipe, polystyrene-aggregate, and pipe-and-aggregate) on in-product solution storage and biomat thickness under increased loading rates in a profile-limited soil in northwest Arkansas. The ultimate goal of this study was to estimate the long-term acceptance rate (LTAR) for each absorption-field product and architecture type. It was hypothesized that 1 ) the gravel-less-pipe and polystyrene-aggregate products would store more solution than the standard pipe-and-gravel product and that chambers and pipe-and-aggregate products would store about the same or less solution under dry- and wet-soil conditions with increased loading rates than the standard pipe-and-gravel product; 2) the 25-cm diameter gravel-less-pipe, the single- and double-bundle polystyrene-aggregate, the pipe-and-tire-chip, the 4.4-m-long 61-cm-width chamber, and the 5.4-m-long 41-cm-width chamber products would have more biomat than the other absorption-field products; and 3) the LTAR for some of the alternative architecture types would differ from that of the standard pipe-and-gravel product.

\section{Materials and Methods}

\subsection{Site Description}

Beginning in 2012, research was conducted at the wastewater treatment facility in Bethel Heights, Arkansas $\left(36^{\circ} 14^{\prime} 12.74^{\prime \prime} \mathrm{N}, 94^{\circ} 7^{\prime} 56.81 " \mathrm{~W}\right)$ as a continuation and extension of the studies conducted by Mathis et al. [14] and Prater et al. [15] that began in 2007. Bethel Heights had an estimated rural population of 2456 in 2013 [19]. The majority of the population has a septic tank that temporarily stores domestic wastewater that is pumped from each tank, approximately 460 connections, to the community wastewater treatment facility [14]. Raw, filtered effluent was used for this study as was used in the previous two studies [14] [15].

The soil at the study site is a Captina silt loam (fine-silty, siliceous, active, mesic Typic Fragiudults) with silty pedisediment over silty and clayey residuum weathered from cherty limestone and is moderately well-drained [20]. The Captina soil is considered a profile-limited soil due to the presence of a fragipan between approximately 43 and $63 \mathrm{~cm}$ below the soil surface, which inhibits vertical water movement causing redoximorphic features to form at shallow soil depths [20]. Initial soil characteristics reported by Mathis et al. [14] revealed low-chroma (i.e., chroma $\leq 2$ ) redoximorphic features present at depth of 33 to $61 \mathrm{~cm}$, which indicates a seasonally fluctuating water table at the site. Clay contents in the 45- to 55-cm depth interval (i.e., the depth of the bottom of the trenches all products were installed in) ranged from 0.2 to $0.37 \mathrm{~g} \cdot \mathrm{g}^{-1}$, which corresponded to soil textures ranging from loam to silt loam to clay loam, coarse fragments ranged from 0 to $19 \%$ (gravimetric basis), and estimated saturated hydraulic conductivity ranged from 1.6 to $15.0 \mathrm{~mm} \cdot \mathrm{hr}^{-1}$ [14].

The mean annual temperature from 1981 to 2010 in northwest Arkansas was $13.0^{\circ} \mathrm{C}$ and the average annual rainfall was $119.6 \mathrm{~cm}$ [21]. Vegetation at the site consisted of a mix of Bermuda grass (Cynodon dactylon), blue grass (Poa pratensis), tall fescue (Festuca arundinacea), plantain (Plantago lanceolata), and white clover (Trifolium repens) with the predominant species being tall fescue and white clover [14].

\subsection{Products Being Evaluated and Experimental Design}

Between mid-December 2006 and late May 2008, 13 absorption-field products of four different architecture types (i.e., chamber, pipe-and-aggregate, gravel-less-pipe, and polystyrene-aggregate) were installed at the BHWTF [14]. The products used in this study are relatively common throughout the US. All trenches were excavated to a depth of $46 \mathrm{~cm}$ using a track hoe with trench widths varying with the specific product (Table 1, Figure 1). Trench bottoms were adjusted with a laser level so both ends had the same elevation. Trenches were excavated approximately $6 \mathrm{~m}$ from each other in all directions. Nine of the 13 individual products were donated from their manufacturers and were installed by company representatives. A licensed Arkansas Department of Health official installed the remaining four products.

Five chamber products were used in this study. The five chamber products had nominal widths of 31-, 56-, 61-, 41-, and 61-cm with trench widths of 46, 61, 61, 41, and $61 \mathrm{~cm}$, respectively, and product lengths of 4.4, 4.4, 4.4, 5.4, and $5.4 \mathrm{~m}$, respectively (Table 1 ).

Two gravel-less-pipe products were used in this study. The ADS (Advanced Drainage Systems, Hilliard, Ohio) SB2 pipe system consisted of a polyethylene pipe wrapped in nylon. (Note: The mention of any commercial products does not mean or provide endorsement by the Division of Agriculture University of Arkansas System.) 


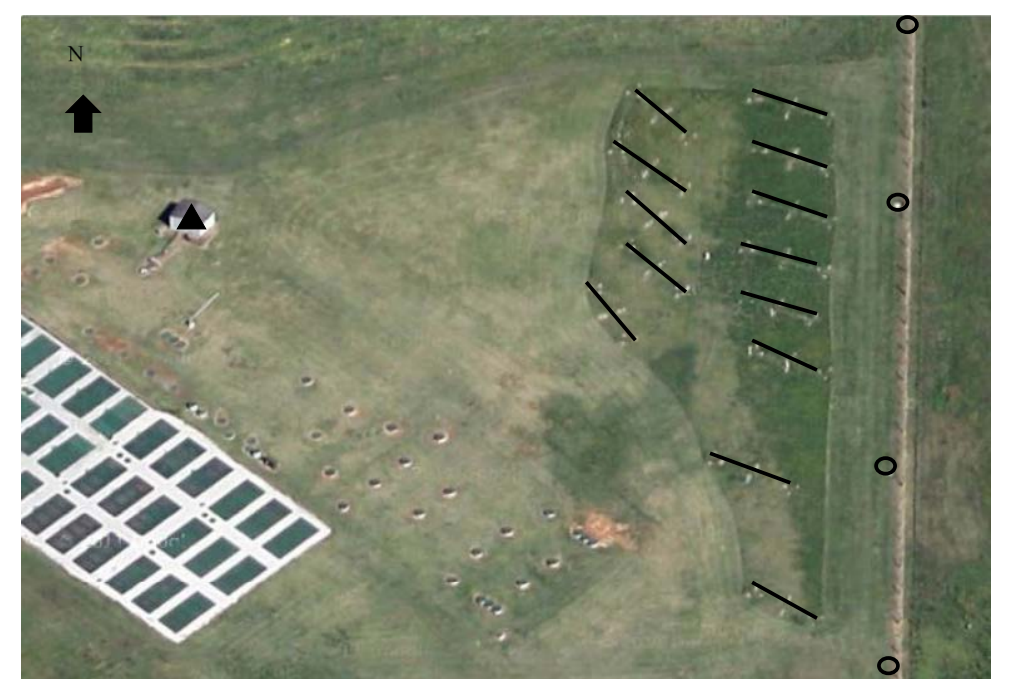

Figure 1. Aerial view of the 13 products (solid, black lines) installed at the Bethel Heights Wastewater Treatment Plant in Bethel Heights, AR. Groundwater monitoring wells (open, black circles) and the pump house (solid, black triangle) are also depicted. Annotations on the image are not drawn to scale.

A 20-cm-diameter product was placed in a trench width of $41 \mathrm{~cm}$ and a $25-\mathrm{cm}$-diameter product was placed in a trench $46 \mathrm{~cm}$ wide with both products being $6.1 \mathrm{~m}$ long (Table 1).

Two polystyrene-aggregate products were used in this study. One product consisted of a 30.5-cm-diameter single bundle of polystyrene aggregates encasing a 10.16-cm-diameter perforated pipe and the other product consisted of a single bundle plus a second 30.5-cm-diameter bundle that only has polystyrene aggregates in it with no pipe. The single- and double-bundle, polystyrene-aggregate products were installed in trenches 30 - and 61-cm wide, respectively, and both products were $6.1 \mathrm{~m}$ long (Table 1).

Four pipe-and-aggregate products were used in this study: pipe-and-gravel with a 30-cm, 45.7-, 61-cm wide trench and pipe-and-tire-chip with a 61-cm-wide trench (Table 1). The final product installation requirements of each of the four pipe-and-aggregate products consisted of a 10.2-cm-diameter perforated PVC pipe laid on top of a minimum of $15.2 \mathrm{~cm}$ of aggregate (i.e., gravel or tire chips) [17]. A minimum of $5.1 \mathrm{~cm}$ of aggregate was placed on top of the pipe for a total of $30.5 \mathrm{~cm}$ of aggregate [17]. Geotextile fabric was placed on top of the top layer of aggregate before being backfilled with natural soil [17]. The 30- and 45.7-cm-wide pipe-and-gravel products were experimental and have not been approved for use in Arkansas [14].

\subsection{Effluent Loading Rate and Delivery to Products}

An effluent delivery system consisting of a manifold-type design was installed in March 2013 to control effluent delivery to the individual products. A sewage sump pump (Zoeher Co, PN 53-0002, 0.3 horse power) delivered raw effluent from a storage basin to a manifold piping system. Before reaching the manifolds, effluent passed through a stainless steel filter (Polylok Zabel A1800 Series) with 1.6-mm-wide perforations. Two pressure gauges, as well as two 5.1-cm-diameter gate valves, were used to ensure proper effluent flow into the manifold system. A constant pressure (15.0 $\pm 0.3 \mathrm{kPa})$ was maintained and frequently adjusted manually in both manifolds. A control panel (Aquaworx Infiltrator, BR-685861), with a timer and data module, monitored the time that the pump ran and how many times per day the pump was cycled. Any changes that needed to be made in the pump cycles were made manually with the data module.

The pipe manifold system itself consisted of two, 5.1-cm-diameter schedule 40 PVC pipes clamped using a 5.1-cm-diameter pipe clamp to the pump house wall. Thirteen, 5.1-cm-diameter schedule 40 PVC tees were used to transmit effluent to individual products. The tees had a 2-cm-diameter threaded reducer where a threaded PVC coupling connected to a PVC universal union. Inside the universal union was a plastic washer with a specific-sized orifice that, along with the pressurized line, controlled the flow rate of effluent to each product. From the union, a threaded-to-slip-fit, 2-cm-diameter elbow connected a clear 5.1-cm-long, 2-cm-diameter, schedule 
40 flexible tube to a longer 2-cm-diameter flex tube via a 2-cm-diameter PVC coupling. The purpose of the clear tubing was to allow visual inspection that effluent passage was occurring successfully through the manifold. The longer flex tube connected to the individual adsorption-field-product outflow pipes, which were $2 \mathrm{~cm}$ in diameter, so that flow occurred via gravity to the individual respective products.

Original effluent loading rates were based on Arkansas State Board of Health [22] and were used by Mathis et al. [14] and Prater et al. [15]. Loading rates were based on soil morphological characteristics surrounding each trench independently from all other trenches, thus exact loading rates differed among all trenches, but the degree of effluent-delivered stress was the same among all trenches [14]. From July 2008 to October 3, 2012, effluent loading rates to the individual products were the same as described by Mathis et al. [14] and Prater et al. [15]. From October 3, 2012 to March 13, 2013 no effluent was delivered to the products to allow the biomat to degrade and in-product solution storage levels to decrease and come to an equilibrium across all products. The new effluent delivery system designed to increase effluent loading rates was constructed during this time period. A 7-month monitoring period, from March 13 to October 4, 2013, with a consistent, approximately double the original effluent loading rate under wet- and dry-soil conditions was used to evaluate each absorption-field product (i.e., Phase I). After the Phase I monitoring period had elapsed, loading rates were approximately doubled again for an additional 7-month (i.e., based on Phase I results) monitoring period from October 8, 2013 to May 29, 2014 (i.e., Phase II). Actual effluent amounts delivered to each product during Phase I and II monitoring were determined by capturing in a bucket and measuring the volume of effluent flowing to each product from the pump manifold for $1 \mathrm{~min}$.

During Phase I, effluent dosing occurred three times per day, for three minutes each dosing. During Phase II, effluent dosing times were increased to four times per day for five minutes each dosing so greater volumes of effluent could be delivered to the products without needing to replace the sump pump for a larger capacity pump. The Phase I and Phase II dosing schedules were slightly different, but more realistic of actual OWTS dosing, from that used in the Mathis et al. [14] and Prater et al. [15] studies, where 35\% of the daily effluent load was delivered between 0500 and 0800 hours, 25\% of the effluent load between 1100 and 1300 hours, and $40 \%$ of the effluent load between 1700 and 2000 hours daily.

A previously reported absorption-field-product, LTAR monitoring method [7] [8] was adopted for use in this study. The criteria of $\geq 20 \mathrm{~cm}$ of water ponding on the infiltrative surface (i.e., trench bottom) for three or more consecutive weeks was used to determine if the LTAR had been achieved or not. The ponding depth of $20 \mathrm{~cm}$ was chosen because Colorado state regulations dictate $15 \mathrm{~cm}$ of aggregate be placed below the distribution pipe [7] [8]. Therefore, $20 \mathrm{~cm}$ of effluent ponding was chosen as a precautionary measure to prevent possible effluent backflow through the discharge pipe into a septic tank [7] [8].

\subsection{In-Product Solution Storage and Biomat Monitoring}

Similar to the methods used by Mathis et al. [14] and Prater et al. [15], in-product solution storage was measured twice weekly using an electronic water-level meter (9-inch English unit model, Durham Geo Slope Indicator, Stone Mountain, GA). Each product had two monitoring ports, approximately $1.5 \mathrm{~m}$ from both ends in the middle of the trench. The water-level meter's probe was lowered into the monitoring port until a surface, either liquid or solid, was reached. The distance from the top of the monitoring ports to the liquid or solid surface was measured. The two measurements per trench were averaged resulting in one measurement per product per measurement date.

Biomat presence inside each product was measured using a wooden dowel and a tape measure, similar to the method used by Prater et al. [15]. The dowel was inserted dry into each monitoring port and twisted to ensure proper biomat coating around the dowel. The biomat created a thick black coating on the dowel if present. When present, a measuring tape was used to measure the biomat thickness on the wooden dowel. The dowel was wiped clean after each insertion into the monitoring ports. If biomat was not present, the dowel appeared brown, indicating the soil at infiltrative surface had been punctured, or colorless, indicating only in-trench solution coated the dowel.

\subsection{Groundwater Monitoring}

The depth to groundwater in four groundwater wells, each 3-m deep, located east of the trenches (Figure 1) was also measured twice weekly using the electronic water-level meter. The groundwater well data were used to determine the soil's condition (i.e., wet or dry) at the time of in-product solution storage and biomat measurements 
and also to monitor groundwater table fluctuations. If the mean depth to free water was less than $91 \mathrm{~cm}$, the soil condition on that date was assigned as wet, and if the depth to free water was greater than $91 \mathrm{~cm}$ across the four wells, the soil condition was assigned as dry [14] [15]. The reason $91 \mathrm{~cm}$ was used to indicate wet-soil conditions was because soil cores prior to product installation revealed gray redox depletions in the soil, indicating the presence of a seasonally fluctuating water table between the 40- and 60-cm depths [14]. Therefore, the 91-cm threshold encapsulated the wet- and dry-soil interface present around all trenches [14].

\subsection{Study Site Maintenance}

A rainfall collection station was installed during summer 2008. The collection station was $1.97 \mathrm{~m}$ above the soil surface and consisted of a standard metal t-post with an 18.1-cm-diameter funnel mounted on top with a 1.2-cm-diameter vinyl tube extending from the bottom of the funnel to a 3.7-L plastic collection bottle. The rainfall collection station was maintained and rainfall measurements were recorded twice weekly.

\subsection{Statistical Analyses}

Similar to previous data analyses [14] [15], the effects of architecture type (i.e., chamber, gravel-less-pipe, polystyrene-aggregate, and pipe-and-gravel), product nested within architecture type, soil condition (i.e., wet and dry), and their interactions on in-product solution storage were evaluated by analysis of variance (ANOVA) using PROC GLM in SAS (version 9.3, SAS Institute Inc., Cary, NC). Architecture type, product nested within architecture type, and soil condition were treated as fixed effects resulting in a single error term. Confidence intervals (95\%) were calculated to compare in-product solution storage of each product to $0 \mathrm{~cm}$ of storage and to the storage observed in the standard pipe-and-gravel system. Following procedures of Prater et al. [15], an ANOVA was also conducted using PROC GLM in SAS to evaluate the effects of architecture type and product within architecture type on biomat thickness. Architecture type and product nested within architecture type were treated as fixed effects resulting in a single error term. As there was only one spatial replication of each absorption-field product, the multiple temporal observations under wet-and dry-soil conditions served as replications used for the ANOVAs. Considering there were 3 to $4 \mathrm{~d}$ between measurements and that products were in nearly constant flux from inputs and outputs of multiple daily dosings of effluent and periodic climatic water, correlations between consecutive measurements in time were assumed negligible, hence the temporal measurements were also assumed independent of one another and represented pseudoreplication among the temporal measurements. When appropriate, means were separated by least significant difference at $\alpha=0.05$.

When biomat was present in the products, linear regression was also conducted using Minitab (version 16, Minitab, Inc., State College, PA) to evaluate biomat thickness trends over time (i.e., increasing, decreasing, or no change). Linear correlations were performed using Minitab to evaluate the relationships between in-product solution storage during wet- and dry-soil conditions for Phase I and II and the relationships with loading rate. Significance was judged at $\mathrm{p}<0.05$ for all statistical analyses.

\section{Results and Discussion}

From July 2008 to October 3, 2012, the products were loaded at maximum allowable rates based on state of Arkansas regulations [14] [15] [22]. With no effluent being delivered to the products between October 3, 2012 and March 13, 2013, in-product solution storage and biomat thickness were greatly reduced over time. Biomat degraded in all products (data not shown) by 96 days prior to beginning Phase I monitoring and in-product solution storage was assumed to be only affected by climatic water additions, which resulted in some minor differences in solution storage among some of the products when Phase I began (data not shown). Before Phase I loading began on March 13, 2013, solution storage in all of the products had achieved $0 \mathrm{~cm}$, except for in the pipeand-tire-chip product, which had an in-product solution storage of $17.3 \mathrm{~cm}$. As reported in Prater et al. [15], this particular pipe-and-tire-chip product likely had infiltrative-surface obstructions due to the tire chips flattening out on the infiltrative surface preventing water from infiltrating into the soil and causing extra ponding in the product.

\subsection{Phase I Monitoring}

During Phase I of this study, effluent loading rates for all products were approximately doubled from the maxi- 
mum allowable loading rates [14] [15] [22]. Measured effluent delivery volumes to the absorption-field products ranged from 34.3 and $231.5 \mathrm{~L} \cdot \mathrm{d}^{-1}$ (Table 2). A total of $92.0 \mathrm{~cm}$ of rainfall occurred at the study site during the 205-d, Phase I monitoring period (Figure 2). During Phase I, there were 36 dry-soil measurement dates and 27 wet-soil measurement dates for a total of 63 measurement dates between March 13 and October 4, 2013 (Figure 2). As expected, in-product solution storage fluctuated with groundwater table fluctuations [16]. As the groundwater approached the soil surface, in-product solution storage increased (Figure 3), as the groundwater declined (Figure 2), in-product solution storage decreased (Figure 3). Some of the products had in-product solution that reached the soil surface (i.e., $46 \mathrm{~cm}$ above the bottom of the trench) on several measurement dates (Figure 3), usually following large rainfall events (Figure 2). However, these surfacings only lasted a day or two.

\subsubsection{Product Performance during Wet- and Dry-Soil Conditions}

In-product solution storage during Phase I differed among architecture types $(\mathrm{p}<0.014)$ and among products within architecture type under dry- and wet-soil conditions $(\mathrm{p}<0.001$; Table 3$)$. The largest numeric in-product solution storage under dry-soil conditions $(17.3 \mathrm{~cm})$ among all products occurred with the pipe-and-tire-chip product (Figure 4). The 25-cm-diameter gravel-less-pipe product had the second greatest numeric (Figure 4) in-product solution storage $(9.8 \mathrm{~cm})$ than any other product under dry-soil conditions, but was statistically similar to the 56-cm-width chamber, the 41-cm-width chamber, the 20-cm diameter gravel-less-pipe, the doublebundle polystyrene-aggregate, and the $46-\mathrm{cm}$ wide pipe-and-gravel products. The smallest numeric in-product solution storage under dry-soil conditions $(0.3 \mathrm{~cm})$ among all products occurred with the standard 61-cm-wide pipe-and-gravel product (Figure 4).

All five chamber products, the 20-cm diameter gravel-less-pipe, the single- and double-bundle polystyreneaggregate, and the 30 -cm-wide pipe-and-aggregate products stored a statistically similar amount as the standard 61-cm-wide pipe-and-gravel product under dry-soil conditions (Figure 4). However, the 25-cm-diameter gravel-less-pipe, 46-cm wide pipe-and-gravel, and the pipe-and-tire-chip products stored significantly more under dry-soil conditions (Figure 4) than the standard pipe-and-gravel product. In contrast to what might be expected, Phase I in-product solution storage under dry-soil conditions was not correlated $(\mathrm{p}>0.05)$ with Phase I loading rates across all products.

Table 2. Summary of original, calculated target, and measured loading rates used during Phase I and II for 13 absorption-field products installed at the Bethel Heights Wastewater Treatment Facility in Bethel Heights, Arkansas.

\begin{tabular}{|c|c|c|c|c|c|c|}
\hline \multirow{3}{*}{ Architecture type } & \multirow{3}{*}{$\begin{array}{l}\text { Product } \\
\text { number }\end{array}$} & \multirow{2}{*}{$\begin{array}{c}\text { Calculated } \\
\text { original } \\
\text { loading } \\
\text { rate }\end{array}$} & \multicolumn{2}{|c|}{ Phase I } & \multicolumn{2}{|c|}{ Phase II } \\
\hline & & & $\begin{array}{l}\text { Calculated } \\
\text { target loading } \\
\text { rate }\end{array}$ & $\begin{array}{c}\text { Mean } \\
\text { measured } \\
\text { flow rate }\end{array}$ & $\begin{array}{l}\text { Calculated } \\
\text { target loading } \\
\text { rate }\end{array}$ & $\begin{array}{l}\text { Mean } \\
\text { measured } \\
\text { flow rate }\end{array}$ \\
\hline & & $L \cdot d^{-1}$ & $L \cdot d^{-1}$ & $L \cdot d^{-1}$ & $\mathrm{~L} \cdot \mathrm{d}^{-1}$ & $\mathrm{~L} \cdot \mathrm{d}^{-1}$ \\
\hline \multirow{5}{*}{ Chamber } & 1 & 35.2 & 70.4 & 72.8 & 143.8 & 114.6 \\
\hline & 2 & 66.2 & 132.4 & 161.6 & 270.7 & 202.7 \\
\hline & 3 & 26.8 & 53.6 & 81.1 & 109.8 & 105.6 \\
\hline & 4 & 34.0 & 68.0 & 117.2 & 173.9 & 177.1 \\
\hline & 5 & 16.4 & 32.8 & 38.5 & 67.7 & 83.5 \\
\hline \multirow{2}{*}{ Gravel-less-pipe } & 6 & 38.9 & 77.8 & 102.4 & 159.4 & 175.0 \\
\hline & 7 & 81.1 & 162.2 & 231.5 & 331.9 & 265.3 \\
\hline \multirow{2}{*}{ Polystyrene-aggregate } & 8 & 21.1 & 42.2 & 34.3 & 86.3 & 149.9 \\
\hline & 9 & 32.4 & 64.8 & 91.5 & 132.5 & 170.3 \\
\hline \multirow{4}{*}{ Pipe-and-aggregate } & 10 & 11.6 & 23.2 & 22.9 & 47.3 & 58.3 \\
\hline & 11 & 31.5 & 63.0 & 93.0 & 129.1 & 132.9 \\
\hline & 12 & 32.3 & 64.6 & 101.4 & 66.2 & 78.7 \\
\hline & 13 & 43.6 & 87.2 & 122.5 & 178.3 & 165.7 \\
\hline
\end{tabular}



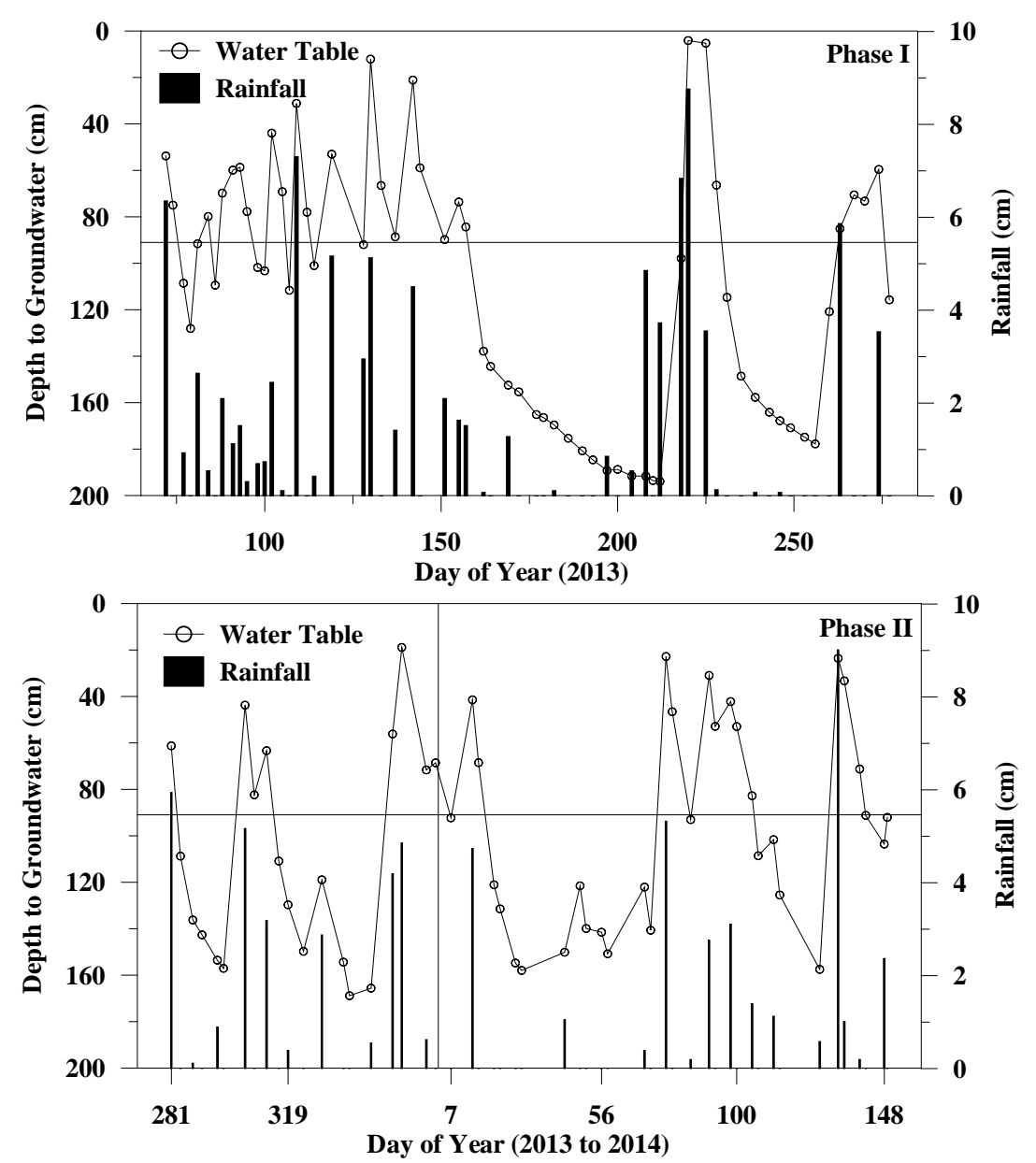

Figure 2. Mean depth to groundwater among four wells adjacent to the study area and rainfall between March 13 [Day of Year (DOY) 74] and October 4 (DOY 277 Phase I), 2013 and between Oct 8 (DOY 281) and May 29 (DOY 149 Phase II), 2014 at the Bethel Heights Wastewater Treatment Plant. The horizontal line at $91 \mathrm{~cm}$ indicates the wet/dry soil-condition interface. The vertical line at DOY 365 represents the separation of the calendar years 2013 and 2014.

The findings under dry-soil conditions in this study differed from that of Mathis et al. [14] who reported that, during the first eight months of effluent loading, no statistical differences in in-product solution storage occurred during dry-soil conditions with original, maximum allowable loading rates. In-product solution storage numerically averaged $0.5 \mathrm{~cm}$ across all products during the first 8 months of loading [14]. The findings of this study also differed from those of Prater et al. [15], where the 30-cm, 46-cm, and 61-cm-wide pipe-and-aggregate products and the 41-cm and 61-cm-width, 5.4-m-long chamber products had, on average after three years of continuous monitoring, in-product solution storage that did not differ from $0 \mathrm{~cm}$ under dry-soil conditions with original, maximum allowable loading rates. Similar to Prater et al. [15], the pipe-and-tire-chip product had greater mean solution storage than the other products, even though the pipe-and-tire-chip product had a greater aggregate porosity (67\%) [14] than the other pipe-and-aggregate and polystyrene-aggregate products. By having a larger aggregate porosity, the pipe-and-tire-chip product would be expected to have a large effluent permeability rate through the product to the underlying soil and store less solution, however, in contrast to that reported in Prater et al. [15], this condition did not occur in this study.

Though some differences were observed during periods of dry-soil conditions, product performance during wet-soil conditions were more important in this study because the absorption-field products' behavior and ability to transmit effluent away from the trench bottom can be inhibited due to hydrologic stresses imposed on them by additional soil water storage from precipitation events [16]. The presence of a shallow, fluctuating water table 


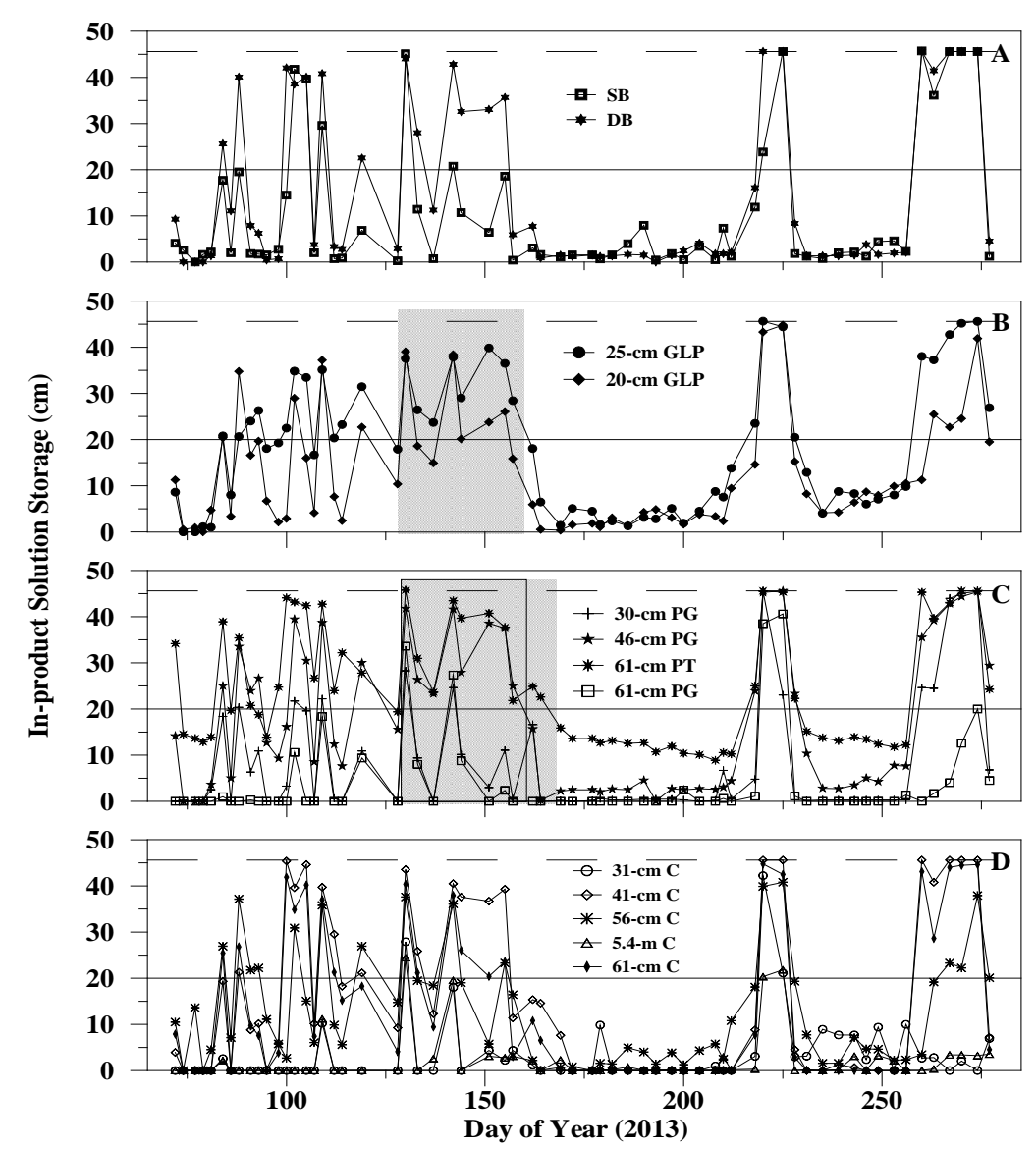

Figure 3. In-product solution storage over time for 13 absorption-field products: (A) single-[SB] and double-bundle [DB] polystyrene-aggregate; (B) 25- and 20-cm diameter gravel-less pipe [GLP]; (C) 30-, 46-, 61-cm wide pipe-and-gravel [PG] and 61-cm wide pipe-and-tire-chip [PT]; and (D) 31-, 41-, 56-cm-width, 61-cmwidth by 4.4-m long, and 61-cm-width by 5.4-m long chambers [C] for the 205-d period between March 13 [Day of Year (DOY) 72] and October 4 (DOY 277), 2013 (Phase I) in Bethel Heights, AR. The horizontal line at $20 \mathrm{~cm}$ indicates the threshold storage at which the long-term acceptance rate (LTAR) exceedance was determined. The gray shaded and boxed region highlights the time period when the products exceeded their estimated LTAR during Phase I. The dashed horizontal line at $45.6 \mathrm{~cm}$ indicates the soil surface.

and the profile limitations of the Captina silt loam also make monitoring the products during wet periods pivotal to understanding product storage capacity and whether or not effluent will surface or not.

Similar to dry-soil conditions, in-product solution storage differed $(\mathrm{p}<0.05)$ among products during wet-soil conditions or periods of climatic stress. In-product solution storage was numerically largest in the 25 -cm gravel-less-pipe, the 46-cm-wide trench pipe-and-gravel, and the 61-cm-wide trench pipe-and-tire-chip products, which did not differ, compared to all other products during wet-soil conditions (Figure 4). The 41-cm-width chamber and the double-bundle polystyrene-aggregate had similar in-product solution storage (Figure 4). The 56-cm-width chamber, 61-cm-width 4.4-m-long chamber, and the 20-cm-diameter gravel-less-pipe products had similar in-product solution storage (Figure 4). The single-bundle polystyrene-aggregate and the 30-cm-wide trench pipe-and-gravel products had similar in-product solution storage under wet-soil conditions to that of the pipe-and-tire-chip product under dry-soil conditions (Figure 4). The 31-cm-width chamber and the 61-cm-width, 5.4-m-long chamber had similar in-product solution storage to the standard 61-cm-wide trench pipe-and-gravel product under wet-soil conditions (Figure 4), all of which had similar solution storages to many of the products during dry-soil conditions. In-product solution storage was smaller in the standard 61-cm-wide trench pipe- 

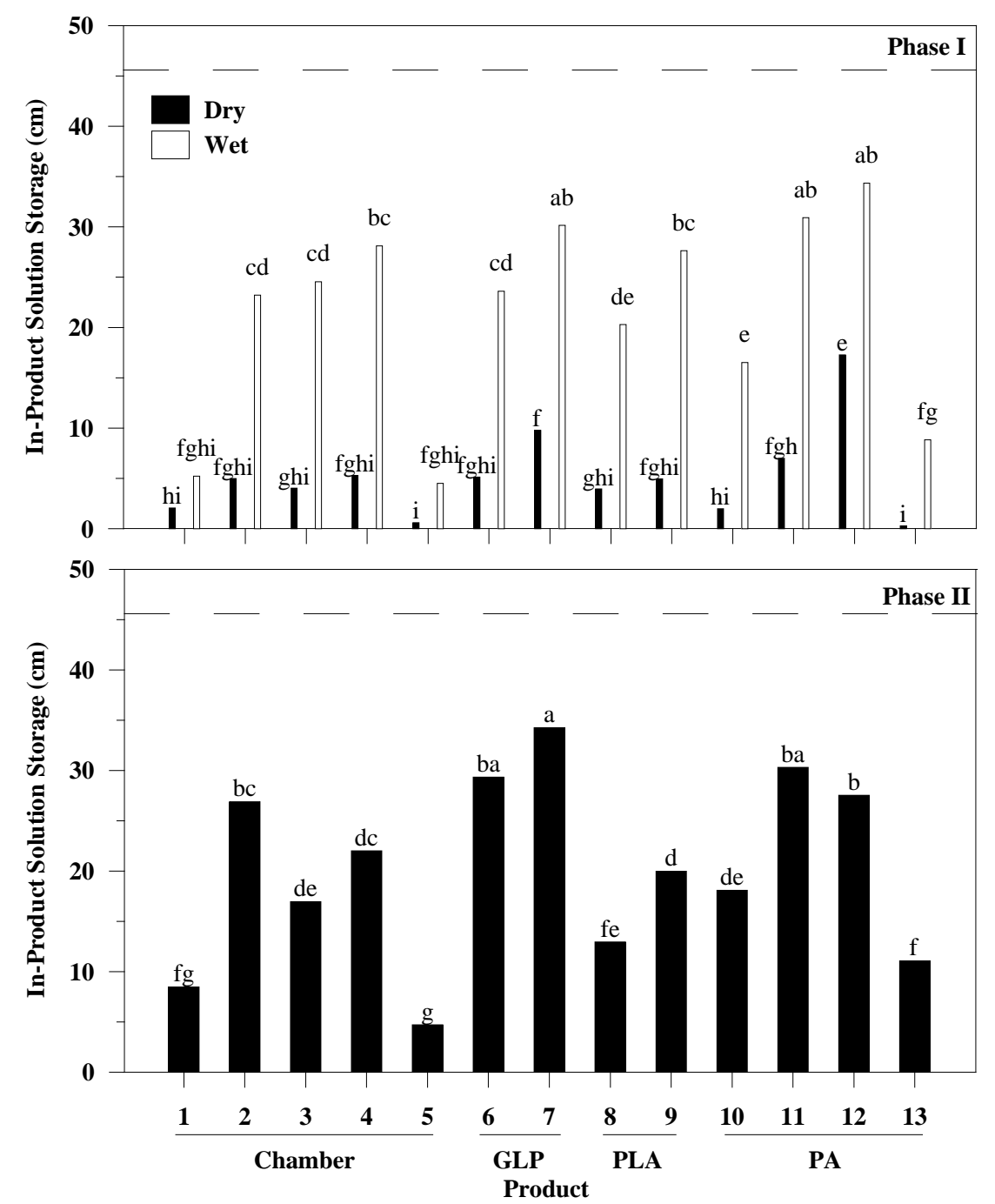

Figure 4. In-product solution storage for the chamber, gravel-less-pipe (GLP), polystyrene-aggregate (PLA), and pipe-and-aggregate (PA) products during wet- and dry-soil conditions for Phase I and, averaged across measurement dates, soil conditions, and products within architecture type, solution storage differences among products during Phase II of this study. Bars for Phase I results with different letters across wet and dry dates are statistically different at $\mathrm{p}<0.05$. Bars for Phase II results with different letters across products are statistically different at $\mathrm{p}<0.05$. The dashed horizontal line at 45.6 $\mathrm{cm}$ indicates the soil surface.

and-gravel and 31- and 61-cm, 5.4-m length chamber products, which did not differ, than all other products under wet-soil conditions (Figure 4). Furthermore, the standard 61-cm-wide trench pipe-and-gravel product had a numerically smaller solution storage under wet-soil conditions than the pipe-and-tire-chip product under dry-soil conditions (Figure 4), which was consistent with results from Prater et al. [15]. However, similar to that for dry-soil conditions, Phase I in-product solution storage under wet-soil conditions was also not correlated ( $>$ 0.05 ) with Phase I loading rate across all products.

Averaged over products within architecture type, in-product solution storage during Phase I monitoring was greater in the gravel-less-pipe and polystyrene-aggregate architecture types, which did not differ, than in the chamber and pipe-and-aggregate architecture types under wet-soil conditions (Figure 5). In-product solution storage under wet-soil conditions was numerically smallest in the chamber architecture type (Figure 5). Under dry-soil conditions, in-product solution storage was smaller $(<8 \mathrm{~cm})$ than all other architecture types under wet-soil conditions (Figure 5). In-product solution storage under dry-soil conditions was greater in the gra- 

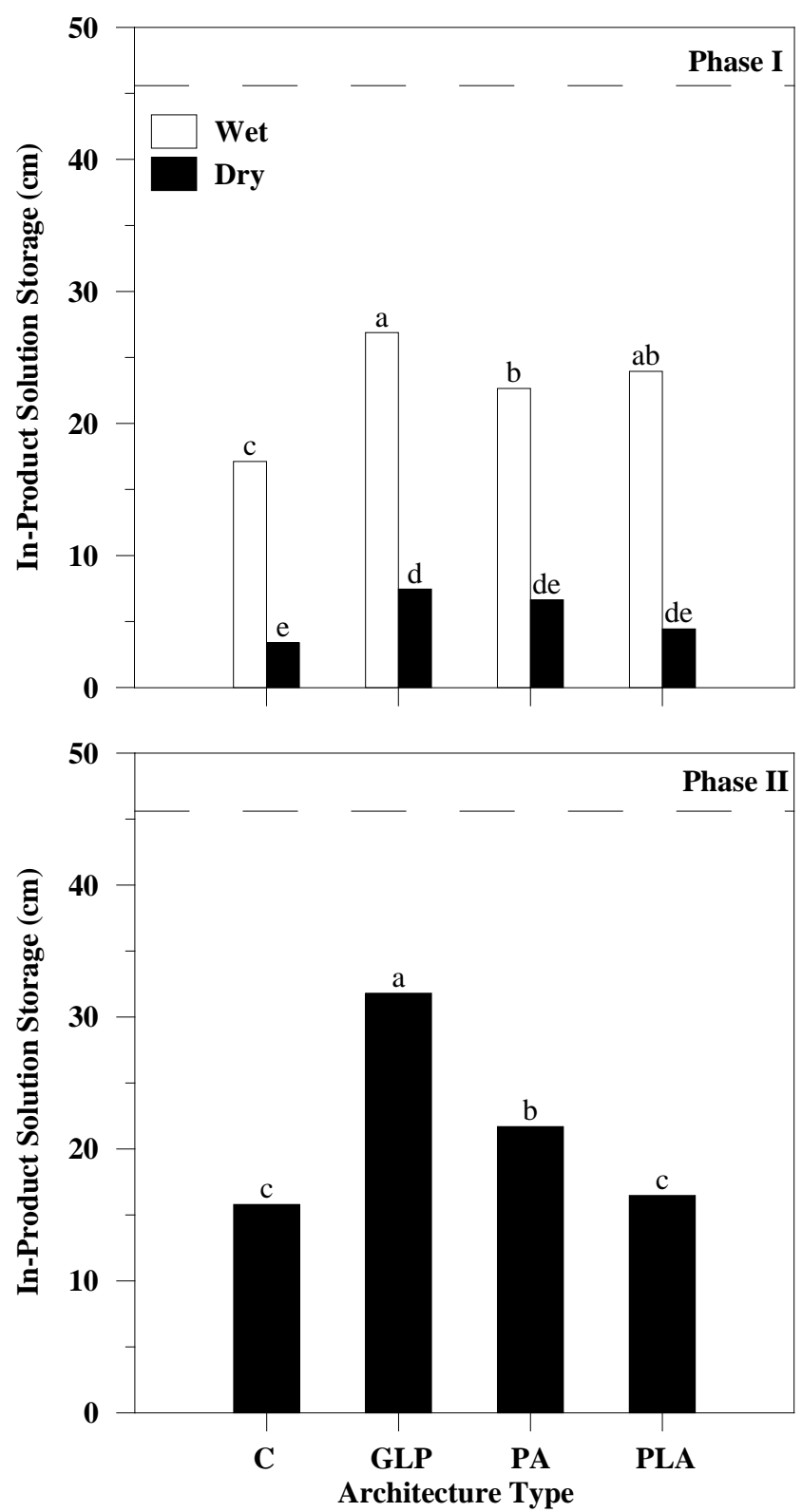

Figure 5. In-product solution storage differences among architecture types [i.e., chamber (C), gravel-less-pipe (GLP), pipe-andaggregate (PA), and polystyrene-aggregate (PLA) products] across wet- and dry-soil conditions averaged over product within architecture type during Phase I and, averaged over product within architecture type and soil condition during Phase II of this study. Bars for Phase I results with different letters across wet and dry dates are statistically different at $\mathrm{p}<0.05$. Bars for Phase II results with different letters across products are statistically different at $\mathrm{p}<0.05$. The dashed horizontal line at $45.6 \mathrm{~cm}$ indicates the soil surface.

vel-less-pipe than in the chamber architecture type (Figure 5). A possible explanation for these differences in architecture type solution storages could be differences in estimated total storage volumes for each product, which ranged from $0.07 \mathrm{~m}^{3} \cdot \mathrm{m}^{-1}$ for the 30 -cm-wide pipe-and-gravel product to $0.2 \mathrm{~m}^{3} \cdot \mathrm{m}^{-1}$ for the 56 -cm-width chamber product [14]. Since all the products have different estimated solution storage capacities, differences in 
in-product solution storage would be expected to be at least slightly different for each product within architecture type. Also, differences in product widths and lengths, which ranged from the 10.2-cm diameter 6.1-m length pipe-and-aggregate products to a 61-cm-width, 4.4-m long chamber product [14], would affect in-product solution storage across architecture types. In other words, the same volume of solution filling the different products would appear to have a numerically different in-product solution storage.

\subsubsection{Biomat Differences}

If present at all, biomat tends to accumulate at the in-flow end of the trench for each product [15]. Prater et al. [15] reported biomat presence in the monitoring port at the end of the trench in one product once during the 3-yr monitoring period at the original, maximum loading rates. However, during Phase I of this study, biomat was detected and measured at the end of the trench 18 times out of a total of 126 biomat measurements made between March 13 and October 4, 2013. Biomat was measured in the monitoring port at the end of the trench of the 56-cm-width chamber product 16 times, the $41-\mathrm{cm}$-width chamber once, and the 20-cm diameter gravel-less product once. In contrast, the gravel-less-pipe, the 30-cm-wide pipe-and-aggregate, and the 61-cm-wide pipeand-tire-chip products did not have biomat present at the in-flow end of the trench at all during Phase I monitoring.

Similar to in-product solution storage, biomat thickness differed among architecture types $(\mathrm{p}<0.001)$ and among products within architecture type $(\mathrm{p}<0.001$; Table 3$)$. Averaged across measurement dates and soil conditions when biomat was present, and similar to results reported by Prater et al. [15], biomat was thicker in the polystyrene-aggregate architecture type $(2.5 \mathrm{~cm})$ than in the other three architecture types, which did not differ among themselves and averaged $<0.1 \mathrm{~cm}$ (data not shown). McKinley and Siegrist [23] conducted a study in which biomat at the infiltrative surface was compared among chamber and pipe-and-gravel products and concluded that there were differences in the composition and amount of organic material in the biomat between the two architecture types, however infiltration rates were not severely affected. Bumgarner and McCray [10] reported the saturated hydraulic conductivity at the infiltrative surface of multiple products in a sandy-loam soil decreased substantially compared to that of native soil when loaded with effluent at rates of 4 and $8 \mathrm{~cm} \cdot \mathrm{d}^{-1}$ due to biomat formation that restricted water/effluent flow. Product architecture (i.e., the netting or the polystyreneaggregates themselves) could have provided a surface for microbial attachment and could be a possible explanation as to why the polystyrene-aggregate product had a thicker biomat.

Averaged across measurement dates and soil conditions, the single-bundle polystyrene-aggregate product had the largest numeric biomat thickness and differed from all other products (Figure 6). The double-bundle polystyrene-aggregate product had the next largest numeric biomat thickness and also differed from all other products (Figure 6). Both polystyrene-aggregate products, however, had similar solution storage to the standard pipeand-gravel product during dry-soil conditions and did not have the greatest solution storage during wet-soil conditions, suggesting that effluent could have been by-passing the biomat layer as suggested in Beal et al. [24]. Biomat thickness was smallest $(<0.21 \mathrm{~cm})$ and did not differ among the remaining 11 products (Figure 6).

Based on regression analyses over the entire duration of Phase I, biomat thickness did not change over time in 10 of the products (Table 4). However, biomat thickness decreased over time $(\mathrm{p}<0.05)$ in the 56-cm-width and

Table 3. Analysis of variance summary of the effects of architecture type, product nested within architecture type, soil condition, and their interactions on in-product solution storage and biomat thickness during Phase I and II of this study.

\begin{tabular}{|c|c|c|c|c|c|c|c|c|}
\hline \multirow{3}{*}{ Source of variation } & \multicolumn{4}{|c|}{ Phase I } & \multicolumn{4}{|c|}{ Phase II } \\
\hline & \multicolumn{2}{|c|}{ Solution storage } & \multicolumn{2}{|c|}{ Biomat } & \multicolumn{2}{|c|}{ Solution storage } & \multicolumn{2}{|c|}{ Biomat } \\
\hline & $\mathrm{df}^{\dagger}$ & $\mathrm{p}$ & $\mathrm{df}$ & $\mathrm{p}$ & df & $\mathrm{p}$ & $\mathrm{df}$ & $\mathrm{p}$ \\
\hline Architecture type (Type) & 3 & $<0.001$ & 3 & $<0.001$ & 3 & $<0.001$ & 3 & $<0.001$ \\
\hline Product (Type) & 9 & $<0.001$ & 9 & $<0.001$ & 9 & $<0.001$ & 9 & $<0.001$ \\
\hline Soil condition (SC) & 1 & $<0.001$ & - & - & 1 & $<0.001$ & - & - \\
\hline Type $\times$ SC & 3 & 0.014 & - & - & 3 & 0.332 & - & - \\
\hline SC × Product (Type) & 9 & $<0.001$ & - & - & 9 & 0.388 & - & - \\
\hline
\end{tabular}

${ }^{\dagger} \mathrm{df}$, degrees of freedom. 
Table 4. Regression analysis of in-product solution storage $(\mathrm{cm})$ and biomat thickness $(\mathrm{cm})$ over time throughout the duration of Phase I (i.e., March 13 through October 4, 2013) and Phase II (i.e., October 8, 2013 through May 29, 2014) of this study and the estimated long-term acceptance rate (LTAR) range for each product based on observations from Mathis et al. [14], Prater et al. [15], and Phases I and II of this study.

\begin{tabular}{|c|c|c|c|c|c|c|}
\hline \multirow[b]{2}{*}{ Architecture type } & \multirow{2}{*}{$\begin{array}{l}\text { Product } \\
\text { number }\end{array}$} & \multicolumn{2}{|c|}{ Phase I } & \multicolumn{2}{|c|}{ Phase II } & \multirow[b]{2}{*}{ Estimated LTAR } \\
\hline & & $\begin{array}{l}\text { Solution } \\
\text { storage }\end{array}$ & $\begin{array}{c}\text { Biomat } \\
\text { thickness }\end{array}$ & $\begin{array}{l}\text { Solution } \\
\text { storage }\end{array}$ & $\begin{array}{c}\text { Biomat } \\
\text { thickness }\end{array}$ & \\
\hline & & & $\bar{L}$ & 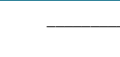 & $\bar{P}$ & $-\mathrm{L} \cdot \mathrm{d}^{-1}-$ \\
\hline \multirow[t]{5}{*}{ Chamber } & 1 & 0.077 & 0.309 & 0.020 & 0.390 & $>115$ \\
\hline & 2 & 0.572 & $0.018^{\dagger}$ & $<0.001$ & 0.121 & 162 to 203 \\
\hline & 3 & 0.936 & $0.011^{\dagger}$ & $<0.001$ & 0.477 & $>106$ \\
\hline & 4 & 0.938 & 0.430 & $<0.001$ & 0.467 & 117 to 177 \\
\hline & 5 & 0.450 & 0.227 & 0.528 & $0.009^{\dagger}$ & $>83$ \\
\hline \multirow[t]{2}{*}{ Gravel-less-pipe } & 6 & 0.504 & - & $<0.001$ & - & 102 to 175 \\
\hline & 7 & 0.446 & 0.831 & $<0.001$ & - & 81 to 231 \\
\hline \multirow[t]{2}{*}{ Polystyrene-aggregate } & 8 & 0.120 & 0.068 & $<0.001$ & $0.003^{\dagger}$ & $>150$ \\
\hline & 9 & 0.689 & $0.001^{\dagger}$ & $<0.001$ & 0.148 & $>170$ \\
\hline \multirow[t]{4}{*}{ Pipe-and-aggregate } & 10 & 0.078 & - & $<0.001$ & - & $>58$ \\
\hline & 11 & 0.562 & 0.422 & 0.004 & - & 31 to 93 \\
\hline & 12 & 0.495 & - & $<0.001$ & - & $\leq 33$ \\
\hline & 13 & 0.380 & 0.567 & $<0.001$ & 0.242 & $>166$ \\
\hline
\end{tabular}

${ }^{\dagger}$ Indicates a statistically significant change in biomat thickness overtime at $\mathrm{p} \leq 0.05$.

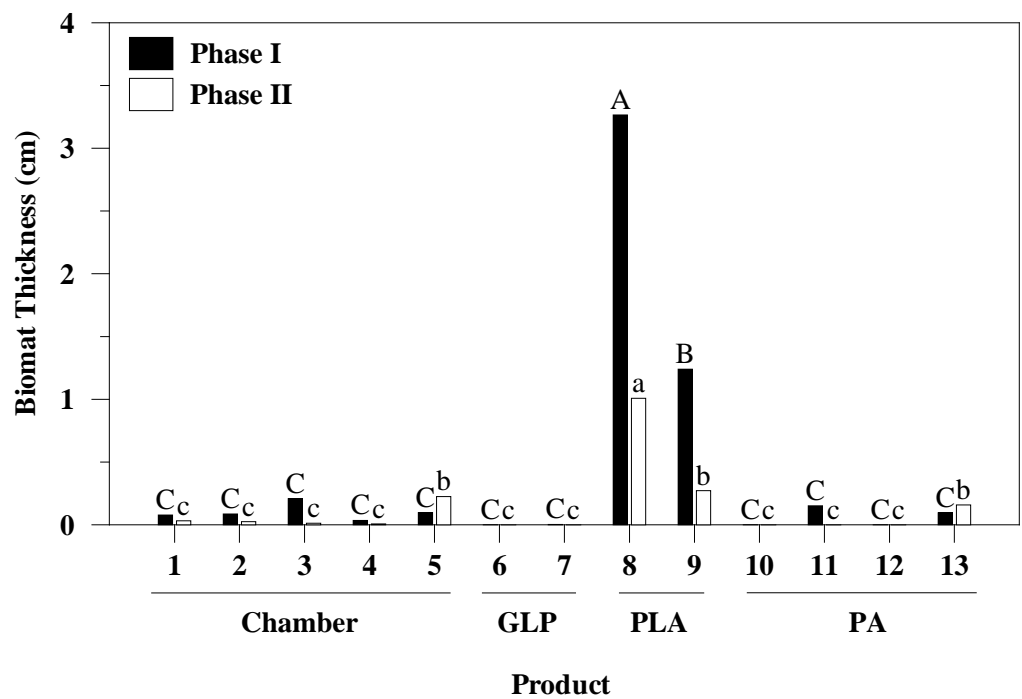

Figure 6. Product within architecture type [i.e., chamber, gravel-less-pipe (GLP), polystyrene-aggregate (PLA), and pipeand-aggregate (PA)] effects on biomat thickness averaged across measurement dates and soil conditions when biomat was present. See Table 1 for specific product number and information characteristics. Product number 13 is the standard pipeand-gravel absorption-field product. Bars within a phase with different letters are different at $\mathrm{p}<0.05$.

the 4.4-m-long, 61-cm-width chamber products. In contrast, biomat thickness increased over time $(\mathrm{p}<0.05)$ in the double-bundle polystyrene aggregate product (Table 4), indicating that biomat thickness continued to fluctuate over time in response to continued effluent dosing as opposed to in the other 10 products where biomat fluctuations occurred in response to wet- and dry-soil conditions. These results differed from the 3-yr study of 
Prater et al. [15], where it was reported that biomat thickness increased over time in the 4.4-m-long, 61-cm-wide chamber, the 25-cm diameter gravel-less-pipe, and the pipe-and-tire-chip products and that biomat thickness decreased over time in the 30-cm-wide pipe-and-aggregate product. Considering 10 of 13 products during Phase I monitoring did not have significant biomat trends over time, biomat clearly fluctuated between measurement periods so as to provide reasonable evidence to support the assumption of negligible correlations between consecutive measurements.

\subsection{Phase II Monitoring}

During Phase II of this study, effluent loading rates were approximately quadrupled from the maximum allowable loading rates based on state of Arkansas regulations [22]. Estimated effluent delivery volumes to the absorption-field products ranged from 58.3 to $265.3 \mathrm{~L} \cdot \mathrm{d}^{-1}$ (Table 2). In contrast to the Phase I monitoring period of this study, a total of $62.0 \mathrm{~cm}$ of rainfall occurred at the study site during the 233-d, Phase II monitoring period between October 8, 2013 and May 29, 2014 (Figure 2). During Phase II, there were 32 dry-soil measurement dates and 20 wet-soil measurement dates for a total of 52 measurement dates (Figure 7). Similar to Phase I,

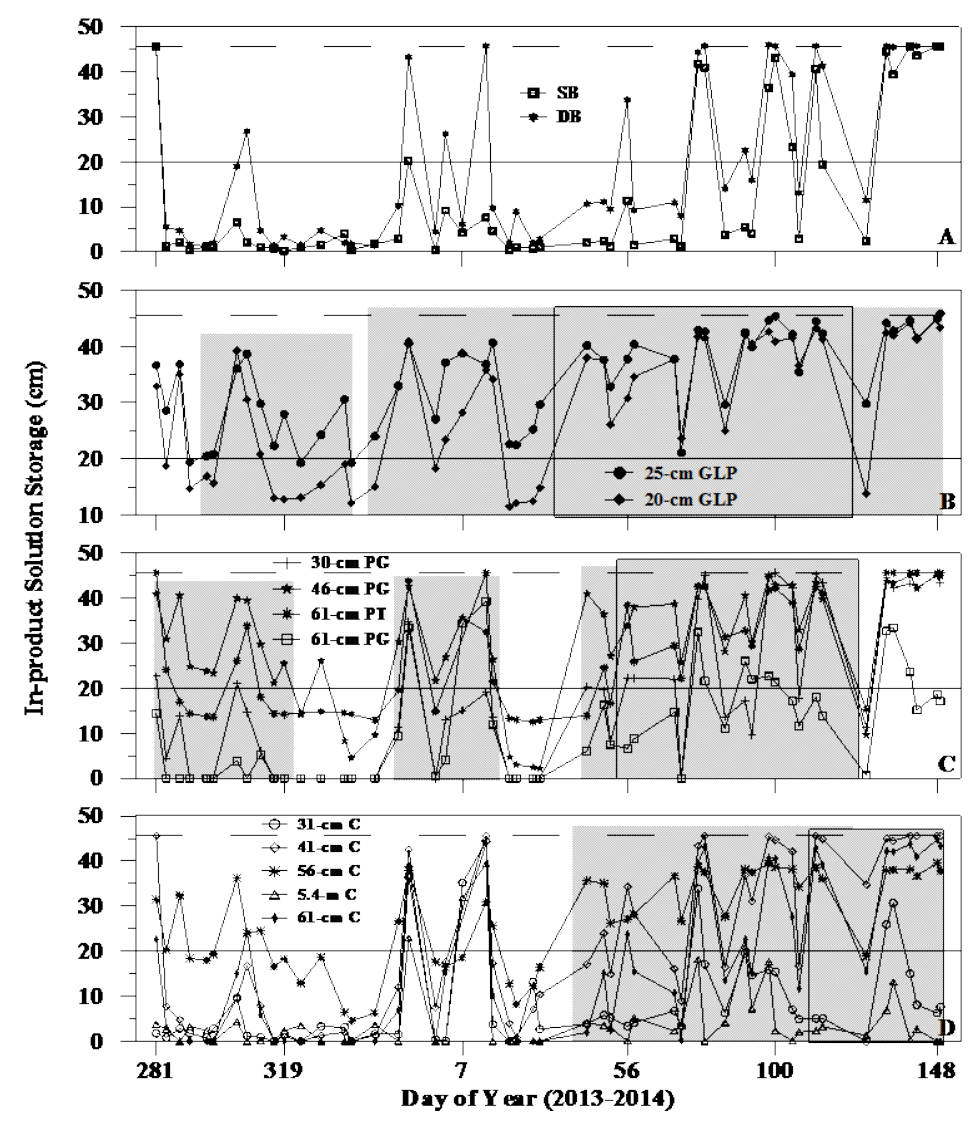

Figure 7. In-product solution storage for 13 absorption-field products: (A) single-[SB] and double-bundle [DB] polystyrene-aggregate; (B) 25- and 20cm diameter gravel-less-pipe [GLP]; (C) 30-, 46-, 61-cm wide pipe-and-gravel [PG] and 61-cm wide pipe-and-tire-chip [PT]; and (D) 31-, 41-, 56-cmwidth, 61-cm-width by 4.4-m long, and 61-cm-width by $5.4-\mathrm{m}$ long chambers [C] for the 233-d period between October 8 [Day of Year (DOY) 281], 2013 and May 29 (DOY 149), 2014 (Phase II) in Bethel Heights, AR. The horizontal line at $20 \mathrm{~cm}$ indicates the threshold storage at which the long-term acceptance rate (LTAR) exceedance was determined. The gray shaded and boxed regions highlight the time period when the products exceeded their estimated LTAR during Phase II. The horizontal dashed line at $45.6 \mathrm{~cm}$ indicates the soil surface. 
some of the products during Phase II also had in-product solution storages that reached the soil surface (i.e., 46 $\mathrm{cm}$ above the bottom of the trench) on several measurement dates (Figure 7), usually after large rainfall events (Figure 2). However, these surfacings were only temporary, lasting only a few days at most.

\subsubsection{Product Performance during Wet- and Dry-Soil Conditions}

During Phase II monitoring, in-product solution storage differed among architecture types $(\mathrm{p}<0.001)$, among products within architecture type ( $<<0.001)$, and between soil conditions $(\mathrm{p}<0.001$; Table 3$)$. The 25-cm diameter gravel-less-pipe product had the greatest numeric $(\mathrm{p}<0.001)$ in-product solution storage during Phase II (Figure 4). The products with the second greatest numeric $(\mathrm{p}<0.001)$ solution storage were the 20 -cm-diameter gravel-less-pipe and the 46-cm-wide pipe-and-gravel products, which did not differ between themselves (Figure 4). The 61-cm-width, 5.4-m-long chamber had numerically the least in-product solution storage and differed from all other products ( $\mathrm{p}<0.001)$ during Phase II (Figure 4). Both Phase II dry- and wet-soil in-product solution storages were not correlated $(p>0.05)$ with Phase II loading rates for each product. The lack of correlation between solution storage and the loading rate for both Phase I and II results provides evidence of the effective, though conservative, approach for assigning loading rates in Arkansas and does not show systematically poor product performance simply due to larger loading rates.

Averaged over products within architecture type and similar to Phase I results during both wet- and dry-soil conditions, in-product solution storage during Phase II monitoring was numerically greater in the gravel-lesspipe architecture type, which differed from the other three architecture types (Figure 5). The second largest numeric in-product solution storage was in the pipe-and-aggregate architecture type, which also differed from each of the other three architecture types (Figure 5). The numerically smallest in-product solution storage was in the chamber and polystyrene-aggregate architecture types, which did not differ, were smaller than that in the other two architecture types (Figure 5). These results were similar to those by Lowe et al. [7] and Lowe and Siegrist [8] who reported that the chamber had a greater infiltration rate, hence lower in-product storage, followed by the pipe-and-gravel, then the polystyrene-aggregate product.

Averaged across architecture type and products within architecture type, the numeric in-product solution storage during wet- $(27.8 \mathrm{~cm})$ was greater $(\mathrm{p}<0.001$; Table 3$)$ than under dry-soil conditions $(15.4 \mathrm{~cm})$. Phase I and II in-product solution storages across all products were significantly correlated during both wet- $(\mathrm{p}<0.001)$ and dry-soil $(\mathrm{p}=0.010)$ conditions. These significant correlations indicated that if a product had low solution storage during Phase I, the same product also had relatively low storage during Phase II and if a product had a larger storage during Phase I, the same product also had relatively larger storage during Phase II.

\subsubsection{Biomat Differences}

During Phase II of this study, biomat was detected and measured at the end of the trench 26 times out of a total of 104 biomat measurements made between October 8, 2013 and May 29, 2014. Biomat was measured at the end of the 56-cm-width chamber product 19 times, the 31-cm-wdith chamber twice, the 41-cm-width chamber four times, and the $20-\mathrm{cm}$ diameter gravel-less-pipe product once. However, the 20- and 25-cm-diameter gravel-less-pipe, the 30- and 46-cm-wide pipe-and-aggregate, and the 61-cm-wide pipe-and-tire-chip products did not have measurable biomat present at the in-flow end of the trench during Phase II. In contrast to Phase I, the 31-cm-width chamber had biomat accumulation at the end of the trench and, also in contrast to Phase I results, the 46-cm-wide pipe-and-aggregate product did not have any biomat present. Biomat presence at the end of the trench of various products indicates the systematic migration of biomat along the trench bottom as the loading rate increased.

Similar to in-product solution storage, biomat thickness differed among architecture types $(\mathrm{p}<0.001)$ and among products within architecture types $(\mathrm{p}<0.001$; Table 3$)$. Similar to Phase I and averaged across measurement dates and soil conditions when biomat was present, biomat was thicker in the polystyrene-aggregate architecture type $(0.6 \mathrm{~cm})$ than in the other three architecture types, which did not differ among themselves and averaged $<0.1 \mathrm{~cm}$ (data not shown). Since a portion of biomat consists of microorganisms [25] and accumulated organic material, both of which can be influenced by the cyclical presence and absence of oxygen, as well as continued and increased effluent dosages [23], the combination of these characteristics could help explain the presence of biomat in the architecture types. Also, the polystyrene-aggregates themselves could have more micro-niches (i.e., cracks or crevices allowing for a greater surface area for microbial attachment) present for sustained and increased microbial growth than the gravel and tire-chip aggregates used in the pipe-and-aggregate 
architecture type and could help explain why the polystyrene-aggregate architecture type had a thicker biomat than the pipe-and-aggregate architecture type.

Averaged across measurement dates and soil conditions, the single-bundle polystyrene-aggregate product had the numerically largest biomat thickness among all 13 products, which differed from the other products (Figure 6). The double-bundle polystyrene-aggregate, the 61-cm-wide pipe-and-gravel, and the 61-cm-width 5.4-m-long chamber products had the next largest numeric mean biomat thicknesses among the products, which did not differ among themselves (Figure 6). Biomat thickness was numerically smallest $(<0.03 \mathrm{~cm})$ and did not differ among the remaining nine products (Figure 6).

Based on regression analyses over the entire duration of Phase II, biomat thickness did not change over time in 11 of the products (Table 4). However, biomat thickness decreased over time $(\mathrm{p}<0.05)$ in the single-bundle polystyrene-aggregate product. In contrast, biomat thickness increased over time $(\mathrm{p}<0.05)$ in the 61-cm-wdith 5.4-m-long chamber product, indicating that biomat thickness continued to fluctuate over time in response to continued effluent dosing as opposed to in the other 11 products where biomat fluctuations occurred in response to wet- and dry-soil conditions. These Phase II results differed from the 3-yr study of Prater et al. [15], where it was reported that biomat thickness increased over time in the 4.4-m-long, 61-cm-wdith chamber, the 25-cm diameter gravel-less-pipe, and the pipe-and-tire-chip products and that biomat thickness decreased over time in the 30-cm-wide pipe-and-aggregate product. Similar to that from Phase I, considering 11 of 13 products during Phase II monitoring did not have significant biomat trends over time, the demonstrated biomat fluctuations between measurement periods provide reasonable evidence in support of the assumption of negligible correlations between consecutive measurements.

\subsection{Estimated Long Term Acceptance Rates}

The LTAR, which could be considered a point of absorption-field-product failure, was assumed exceeded when $\geq 20 \mathrm{~cm}$ of in-product solution storage occurred for longer than three consecutive weeks [7] [8]. The LTAR was likely exceeded for the 25-cm-diameter gravel-less-pipe, the 46-cm-wide pipe-and-gravel, and the 61-cm-wide pipe-and-tire-chip products during Phase I monitoring when the loading rates were approximately doubled from the maximum allowable loading rate based on state of Arkansas regulations (Figure 3). Failure conditions for the 25-cm-diameter gravel-less-pipe and the 46-cm-wide pipe-and-aggregate products occurred for 27 days (Figure 7) from May 10 [day of year (DOY 130)] to June 6, 2013 (DOY 157). Thus, the LTARs for the 25-cm-diameter gravel-less-pipe and the 46-cm-wide pipe-and-aggregate products were likely in the range of the original and the Phase I loading rates for both products (Table 4). Failure conditions for the pipe-andtire-chip product occurred for 34 days (Figure 3) from May 10 (DOY 130) to June 13, 2013 (DOY 164). In the 3-yr Prater et al. [15] study, the LTAR had also likely been exceeded for the pipe-and-tire-chip product on three occasions. Thus, the LTAR for the pipe-and-tire-chip product is likely no greater than the original, maximum allowable loading rate (Table 4). The pipe-and-tire-chip product was reported by Grimes et al. [26] to have similar infiltrative characteristics with pipe-and-aggregate products, however the results of this study showed that the pipe-and-tire-chip product was one of the most inefficient products in terms for promoting effluent transmission from the trench to the soil beneath. The remaining 10 absorption-field products did not have more than 20 $\mathrm{cm}$ of storage for three consecutive weeks during the 3-yr study at their original loading rates [15] or during Phase I monitoring of this study at approximately double the original, maximum loading rate (Figure 3).

Similar to Phase I results, during Phase II monitoring, the likely LTAR was exceeded for the 25-cm-diameter gravel-less-pipe, the 46-cm-wide pipe-and-aggregate, and the pipe-and-tire-chip products (Figure 7). In addition, the likely LTARs were also exceeded during Phase II of this study for the 20-cm diameter gravel-less-pipe and the 56- and 41-cm-width chamber products (Figure 7) when the loading rates had been approximately quadrupled from the original, maximum loading rates used by Mathis et al. [14] and Prater et al. [15]. Failure conditions occurred for the 20-cm-diameter gravel-less-pipe product once during Phase II from February 13 (DOY 44) to April 24 (DOY 114), 2014 (Figure 7). Failure conditions occurred for the 56-cm-width chamber once during Phase II monitoring from February 13 (DOY 44) to April 24 (DOY 114), 2014 (Figure 7). Lastly, the 41-cm-width chamber experienced failure conditions once during Phase II from April 22 (DOY 112) to May 29 (DOY 149), 2014 (Figure 7). Consequently, the LTARs for the 20-cm-diameter gravel-less-pipe and the 56- and 41-cm-width chamber products were likely in the range of the Phase I and the Phase II loading rates (Table 4). The remaining seven absorption-field products did not have more than $20 \mathrm{~cm}$ of storage for three consecutive 
weeks during Phase II monitoring of this study at approximately quadruple their original, maximum loading rate (Figure 7). Therefore, the LTARs for the 30- and 61-cm-wide pipe-and-aggregate, single- and double-bundle polystyrene-aggregate, 31-, 61-, and 61-cm-wdith 5.4-m-long chamber products are likely greater than the Phase II loading rate (Table 4). These observations suggest that biomat does not dictate LTAR because the polystyrene-aggregate products had the thickest biomat and yet did not experience failure, as observed by Beal et al. [24]. However, the 61-cm-wide pipe-and-gravel and the 61-cm-width 5.4-m-long chamber products experienced an increase in biomat thickness from Phase I to Phase II, which could lead to failure in the future.

\subsection{Implications}

Though the number of spatial replications of each OWTS product was limited to one, which limits the general inferences that can be drawn regarding the experimental factors and their wider applicability, the results of this study are still valuable and contribute to our understanding of OWTS behavior and variability. The standard pipe-and-gravel product performed well among the alternative products. The standard product did not have a thick biomat accumulation or a large in-product solution storage during wet- or dry-soil conditions, signifying solution was infiltrating downward into the soil and not surfacing, nor experiencing failure events when the loading rate was even quadrupled. Based on similar measured parameters, the 31-, 61-, and 61-cm-width, 5.4-m-long chamber and the 30-cm-wide pipe-and-gravel products performed equally as well as the standard pipe-and-gravel product. The polystyrene-aggregate products had the thickest biomat, however neither of these products experienced failure events suggesting that biomat likely did not affect in-product solution storage, which was an observation consistent with those of Prater et al. [15] under the maximum allowable loading rate. The two polystyrene-aggregate products also did not have greater solution storage compared to two of the other alternative products, however the two polystyrene-aggregate products had greater solution storage than three other products during wet- and dry-soil conditions.

\section{Summary and Conclusions}

When the loading rates were approximately doubled for each product during Phase I, several products stored more solution under wet- and dry-soil conditions than others. The standard pipe-and-gravel product outperformed all of the alternative products by storing less solution during wet- and dry-soil conditions during Phase I. However, the chamber architecture type outperformed all other architecture types during wet- and dry-soil conditions. Similar to Prater et al. [15], biomat accumulation was thicker in the polystyrene-aggregate architecture type during Phase I. The product with the thickest biomat was the single-bundle polystyrene-aggregate product. Furthermore, biomat thickness increased or decreased over time in many of the products indicating biomat fluctuations as the products experienced wetting and drying cycles. However, it was clear that biomat thickness was not closely related to the products'soil's ability to transmit water and/or effluent from the trench, at least under the conditions at this field site.

When the loading rates were approximately quadrupled for each product during Phase II, there were no differences in solution storage among architecture types and product within architecture type during wet- and drysoil conditions. Similar to Phase I and Prater et al. [15], biomat accumulation was thicker in the polystyreneaggregate architecture type during Phase II. Also similar to Phase I, the product with the thickest biomat was the single-bundle polystyrene-aggregate product, which decreased over the duration of Phase II monitoring, while biomat thickness in most of the other products did not vary over time

During two phases of more than six months of continuous monitoring, several of the products experienced failure conditions (i.e., solution storage $\geq 20 \mathrm{~cm}$ for more than three consecutive weeks) with increased loading rates, while several other products experienced no failure. Though large variability was encountered in this field study after more than four years of observations, results suggests that current loading rates established by Arkansas state regulations may be too conservative for some products, while the current maximum allowable loading rates based on soil morphology and the storage concept are likely sufficiently conservative for other products.

\section{Acknowledgements}

Funding for this project was providing by the Arkansas Department of Health's Individual Sewage Disposal System Advisory Committee. 


\section{References}

[1] United States Environmental Protection Agency (2008) Septic System Fact Sheet. EPA \# 832-F-08-057. Office of Wastewater Management. http://nepis.epa.gov/Adobe/PDF/P1004624.pdf

[2] United States Census Bureau (1990) Census of Housing. Historical Census of Housing Tables: Sewage Disposal. http://www.census.gov/hhes/www/housing/census/historic/sewage.html

[3] Brahana, J.V. (1995) Controlling Influences on Ground-Water Flow and Transport in the Shallow Karst Aquifer of Northeastern Oklahoma and Northwestern Arkansas. Arkansas Water Resources Center, Fayetteville, 25-33.

[4] Owen, M.R. and Pavlowsky, R.T. (2011) Base Flow Hydrology and Water Quality of an Ozarks Spring and Associated Recharge Area, Southern Missouri, USA. Environmental Earth Sciences, 64, 169-183. http://dx.doi.org/10.1007/s12665-010-0836-4

[5] Jarvie, H.P., Sharpley, A.N., Brahana, J.V., Simmons, T., Price, A., Neal, C., Lawlor, A., Sleep, D., Thacker, S. and Haggard, B. (2014) Phosphorus Retention and Remobilization along Hydrological Pathways in Karst Terrain. Environmental Science \& Technology, 48, 4860-4868. http://dx.doi.org/10.1021/es405585b

[6] Tackett, K.N., Lowe, K.S., Siegrist, R.L. and Van Cuyk, S.M. (2004) Vadose Zone Treatment during Reclamation as Affected by Infiltrative Surface Architecture and Hydralic Loading Rate. In: Mankin, K.R., Ed., Onsite-Wastewater Treatment, ASAE, American Society of Agricultural Engineers, St. Joseph, 655-667.

[7] Lowe, K.S., Siegrist, R.L. and Tackett, K.N. (2006) Hydraulic Loading Rate and Infiltrative Surface Architecture Effects on Septic Tank Effluent Treatment during Soil Infiltration. National Onsite Wastewater Recycling Association, NOWRA 15th Annual Conference, Denver, 28-31 August 2006.

[8] Lowe, K.S. and Siegrist, R.L. (2008) Controlled Field Experiment for Performance Evaluation of Septic Tank Effluent Treatment during Soil Infiltration. Journal of Environmental Engineering, 134, 93-101. http://dx.doi.org/10.1061/(ASCE)0733-9372(2008)134:2(93)

[9] Quisenberry, V., Brown, P. and Smith, B. (2006) In-situ Liquid Storage Capacity Measurement of Subsurface Wastewater Absorption System Products. Journal of Environmental Health, 69, 9-15.

[10] Bumgarner, J.R. and McCray, J.E. (2007) Estimating Biozone Hydraulic Conductivity in Wastewater Soil-infiltration Systems Using Inverse Numerical Modeling. Water Research, 41, 2349-2360. http://dx.doi.org/10.1016/j.watres.2007.02.040

[11] Amerson, E.S., Tyler, E.J. and Converse, J.C. (1991) Infiltration as Affected by Compaction, Fines, and Contact Area of Gravel. Small Scale Waste Management Project. School of Natural Resources, College of Engineering, College of Agricultural and Life Sciences, University of Wisconsin, Madison.

[12] Lerch, R.N. (2011) Contaminant Transport in Two Central Missouri Karst Recharge Areas. Journal of Cave and Karst Studies, 73, 99-113. http://dx.doi.org/10.4311/jcks2010es0163

[13] Teppen, B.J., Rutledge, E.M., Wolf, D.C. and Gross, M.A. (1992) Septic Tank Filter Field Designs for Soils with Perched Aquic Conditions. In: Kimble, J.M., Ed., Proceedings of the Eighth International Soil Correlation Meeting: Characterization, Classification, and Utilization of Wet Soils, USDA, Soil Conservation Service, National Soil Survey Center, Lincoln, 279-287.

[14] Mathis, A.J., Brye, K.R. and Dunn, S. (2011) Preliminary Evaluation of Septic-System Absorption-Field Architecture Types in a Profile-Limited Soil. Journal of Environmental Quality, 40, 1661-1673. http://dx.doi.org/10.2134/jeq2011.0015

[15] Prater, N.J.M, Brye, K.R., Dunn, S., Soerens, T.S., Sharpley, A.N., Mason, E. and Gbur, E.E. (2013) Effluent Storage and Biomat Occurrence among Septic System Absorption-Field Architectures in a Typic Fragiudult. Journal of Environmental Quality, 42, 1213-1225. http://dx.doi.org/10.2134/jeq2012.0373

[16] Rutledge, E.M., Teppen, B.J., Mote, C.R. and Wolf, D.C. (1993) Designing Septic Tank Filter Fields Based on Effluent Storage during Times of Climatic Stress. Journal of Environmental Quality, 22, 46-51. http://dx.doi.org/10.2134/jeq1993.00472425002200010006x

[17] Arkansas Department of Health (1994) Rules and Regulations Pertaining to Sewage Disposal Systems, Designated Representatives, and Installers. A.C.A. 14-236-101 et seq., Environmental Program Services Division of Environmental Health Protection, Little Rock.

[18] Craun, G.F. (1985) A Summary of Waterborne Illness Transmitted through Contaminated Groundwater. Environmental Health, 48, 122-127.

[19] United States Census Bureau (2010) Population Finder. Bethel Heights City, Arkansas. http://factfinder2.census.gov/faces/tableservices/jsf/pages/productview.xhtml?pid=PEP_2013_PEPANNRES

[20] Natural Resources Conservation Service (2012) Web Soil Survey. http://websoilsurvey.nrcs.usda.gov/app/HomePage.htm 
[21] National Oceanic and Atmospheric Administration (2010) Bentonville, Arkansas Climatology: Benton County. http://www.srh.noaa.gov/tsa/?n=climo_benton

[22] Arkansas State Board of Health (2012) Act 402 of 1977: Rules and Regulations Pertaining to Onsite Wastewater Systems. A.C.A. 14-236-101 et seq., Little Rock. http://www.healthy.arkansas.gov/aboutADH/RulesRegs/OnsiteWastewaterSystems.pdf

[23] McKinley, J.W. and Siegrist, R.L. (2010) Accumulation of Organic Matter Components in Soil under Conditions Imposed by Wastewater Infiltration. Soil Science Society of America Journal, 74, 1690-1700. http://dx.doi.org/10.2136/sssaj2009.0395

[24] Beal, C.D., Gardner, E.A., Kirchof, G. and Menzies, N.W. (2006) Long-Term Flow Rates and Biomat Zone Hydrology in Soil Columns Receiving Septic Tank Effluent. Water Research, 40, 2327-2338. http://dx.doi.org/10.1016/j.watres.2006.04.018

[25] Tomaras, J., Sahl, J.W., Siegrist, R.L. and Spear, J.R. (2009) Microbial Diversity of Septic Tank Effluent and a Soil Biomat. Applied and Environmental Microbiology, 75, 3348-3351. http://dx.doi.org/10.1128/AEM.00560-08

[26] Grimes, B.H., Steinbeck, S. and Amoozegar, A. (2003) Analysis of Tire Chips as a Substitute for Stone Aggregate in Nitrification Trenches of Onsite Septic Systems: Status and Notes on the Comparative Macrobiology of Tire Chip Versus Stone Aggregate Trenches. Small Flows Quarterly, 4, 18-23. 